\title{
A Simulation Analysis of the Introduction of an Environmental Tax to Develop Biomass Power Technology in China
}

\author{
Shanshan Wang ${ }^{1}$, Feng Xu ${ }^{1}$, Nan Xiang ${ }^{1}$, Takeshi Mizunoya ${ }^{1}$, Helmut Yabar ${ }^{1}$, \\ Yoshiro Higano ${ }^{1}$ \& Ruiqin Zhang $^{2}$ \\ ${ }^{1}$ Graduate School of Life and Environmental Sciences, University of Tsukuba, Japan \\ ${ }^{2}$ Institute of Environmental Sciences, Zhengzhou University, Zhengzhou, China \\ Correspondence: Shanshan Wang, Graduate School of Life and Environmental Sciences, University of Tsukuba, \\ 1-1-1 Tennodai, Tsukuba, Ibaraki 305-8572, Japan. Tel: 81-29-853-7255. E-mail: \\ wangshanshan543@gmail.com
}

Received: February 1, 2012 Accepted: March 23, 2012 Online Published: December 21, 2012

doi:10.5539/jsd.v6n1p19 URL: http://dx.doi.org/10.5539/jsd.v6n1p19

\begin{abstract}
Despite rapid growth in the past few decades, biomass power development in China continues to face several barriers, such as a lack of supporting policies and core technologies. This study proposes the introduction of an environmental tax to promote biomass power technology development in China. We construct a dynamic input-output model to evaluate the effects and economic feasibility of an environmental tax, considering the interrelationships among China's economy, energy and environment. The GDP is maximized as the objective function subject to greenhouse gas (GHG) emissions constraints and a series of socio-economic constraints. The model uses 2007 as the base year and 2020 as the target year. The simulation results illustrate that a 10 Yuan/ $\mathrm{tCO}_{2} \mathrm{e}$ carbon tax is sufficient to stimulate biomass technology development, in addition to economic development and GHG emissions mitigation. According to the simulation, the total biomass power generation from 2007 to 2020 with the environmental tax will be 2,334 TWh, the annual growth rate of GDP will be 9 percent and the GHG emissions intensity will be $0.15 \mathrm{kgCO}_{2} \mathrm{e} / \mathrm{Yuan}$, a 46.5 percent reduction compared with 2005 GHG emission intensity levels. Electricity substitution and industrial structure adjustment are two key approaches to achieve the optimization of economic development and GHG emissions mitigation in the model. Furthermore, the introduction of an environmental tax is shown to be economically feasible by the cost-benefit analysis.
\end{abstract}

Keywords: dynamic input-output model, environmental tax, biomass power technology

\section{Introduction}

As a renewable energy, biomass power has attracted more attention and has had rapid growth in the past several decades in China (Zhao, 2011). By the end of 2008, the total installed capacity of biomass power generation in China was 3,150 MW. The Chinese government established a development target for biomass power in the "Medium-long-term renewable energy development plan", which stated that the total installed capacity of biomass power should reach 30,000 MW by 2020 (NDRC, 2007). However, the actual progress of biomass power development in China has not been sufficient to meet these targets. In fact, because of low commercial profits, many biomass power plants in China must rely on government subsidies to maintain operations (Zhao, 2012). The reasons for this situation, which are analyzed briefly, are the absence of supporting policies and core biomass power technologies. Due to this lack of incentive policies and proper technologies, the development of the biomass power generation industry has many barriers in China, such as the high construction cost of a biomass power plant, the high cost of raw materials and fewer financing channels. Therefore, in this paper, we propose the introduction of an environmental tax to promote biomass power technology development in China.

The first consideration of this study is biomass power generation technology. There are many types of biomass power technologies, such as municipal waste incineration, gasification power generation, biogas power generation and direct straw combustion, which is the most common technology in China (Zhao, 2012). Considering the typical characteristics of biomass power generation, we chose the advanced domestic technology of direct straw combustion at the "Beiliu Kaidi Biomass Power Project", a registered CDM project. In this paper, 'biomass power technology' refers to this technology. The key technical specifications of the boiler, 
turbine and generator are obtained from the project design document. The second consideration of this study is the raw material. As the world's largest agricultural country, China has ample straw crop resources (Yang, 2010; Liu, 2007; Liu, 2008; Zhou, 2011). In 2007, the total potential crop output, including food crops, oil crops and cottons, among others, was 658 million tons, and the theoretical production of straw crops was 533 million tons (Yang, 2010). However, greater than 50 percent of straw crops were burned in an uncontrolled manner, rather than for biomass energy generation, resulting in incomplete combustion (NDRC, 2011). The open burning of straw crops is a serious issue in China, and the government has established special regulations to prohibit burning straw crops in fields (NDRC, 2011). However, due to the flagging development of straw crop utilization industries, open burning is still very common during the harvest season and has many negative impacts on society, such as the increased frequency of fire disasters during the harvest season and the increased concentration of atmospheric particles that are harmful to human health $(\mathrm{Bi}, 2010)$. Moreover, the open burning of straw crops is an important greenhouse gas (GHG) emissions source in China, because the incomplete combustion of straw crops would emit copious amounts of methane and nitrous oxide, which have considerably higher global warming potentials (GWP), 23 and 296, respectively, than carbon dioxide. In 2007, the GHG emissions from the open burning of straw crops were 17.63 million ton $\mathrm{CO}_{2} \mathrm{e}$. Therefore, the promotion of the development of the biomass power industry by using direct straw combustion technology is significant.

Few studies of biomass power development in China have proposed new policies to promote the development of the biomass power industry in China. Zhao and Yan assessed the strengths, weaknesses, opportunities, and threats of the biomass power generation industry in China by using a qualitative analysis method (Zhao, 2012) and provided an overview of the status quo. Wu et al. presented an economic analysis of biomass gasification and power generation in China (Wu, 2002) and found strong links between installed capacity and cost. In regards to the policy evaluation of an environmental tax, many studies have been performed in Japan. Higano derived the environmental value-added tax based on the input-output and LINGO programming models (Higano, 1996). Uchida has constructed an input-output model to evaluate the efficacy of a carbon tax in promoting the effective use of potential energy of waste in Japan (Uchida, 2006). Li designed a dynamic environmental-social-economic model to enhance E-waste recycling by introducing recycling taxes ( $\mathrm{Li}, 2012)$. However, Li did not assess the economic feasibility of the proposed policies, which is critical to policy decisions. Therefore, our study proposes an environmental tax to promote biomass power development in China and evaluates its effects and economic feasibility.

The research objectives of this paper are to:

$>$ Construct a comprehensive dynamic input-output model using a simulation approach based on the materials balance, electricity supply and demand balance, commodities market flow balance and capital market flow balance, to offer an effective method to mitigate global warming in China;

$>$ Analyze the effects of introducing an environmental tax to develop biomass power technology in China by simulating the most likely development pathways under different scenarios in an integrated model that would simultaneously achieve GHG emissions mitigation and socio-economic development targets.

$>$ Evaluate the economic feasibility of the policy proposal through cost-benefit analysis to provide recommendations to policymakers.

\section{Methodology}

Combined with the scenario analysis method, we constructed a dynamic simulation model based on input-output theory. Input-output theory was developed by Wassily Leontief in 1966 (Leontief, 1966) and describes the interdependencies between different branches of the national economy. The input-output model is widely used in comprehensive policy evaluations (Higano, 1996; Uchida, 2006; Li, 2012). The simulation is completed using LINGO, which is an optimization modeling software for linear, nonlinear and integer programming developed by LINDO Systems.

\subsection{Model Framework}

As indicated in Figure 1, the dynamic simulation model consists of an objective function and a series of subjective functions, including a commodity flow balance module, value flow balance module, electricity balance module and macroeconomic module. The objective function of this model is to maximize total GDP from 2007 to 2020, subject to all modules. 


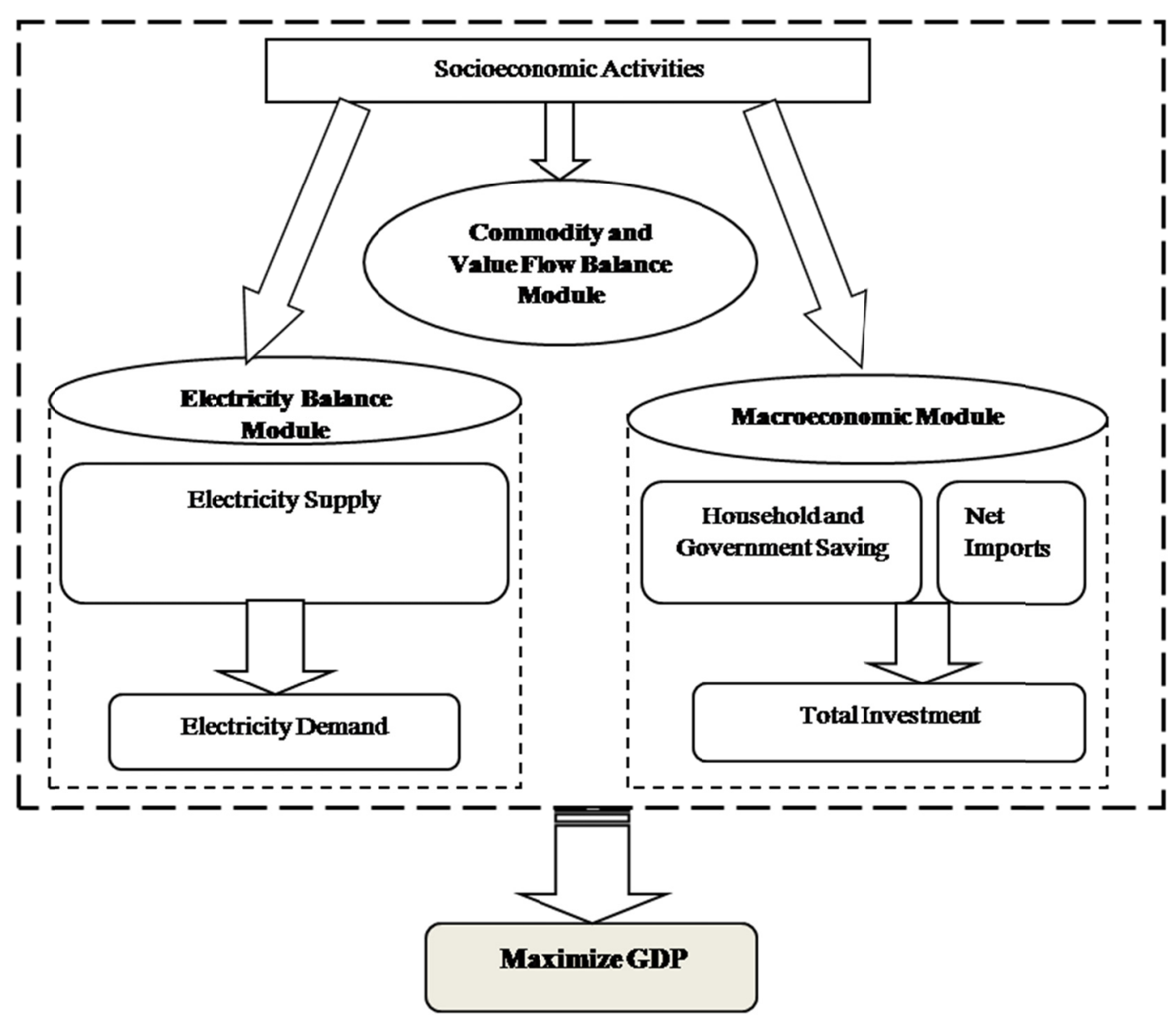

Figure 1. Model framework

There are four economic entities in this model: industry, government, household and the globe. As indicated in Figure 2, government revenue is composed of indirect taxes from industries, income taxes from households, and carbon taxes from usual industries and the thermal power industry. Government expenditures include government purchases, government saving and subsidies to the biomass power industry. The entire carbon tax will be used as a subsidy. Household income is spent in three categories: household consumption, income tax and household saving. We consider the balances in two markets: the capital market and commodity market. In the capital market, government saving, household saving and net exports will be used as industry investments. The behavior in the commodity market will be presented as the "commodity flow balance" in the following section. 


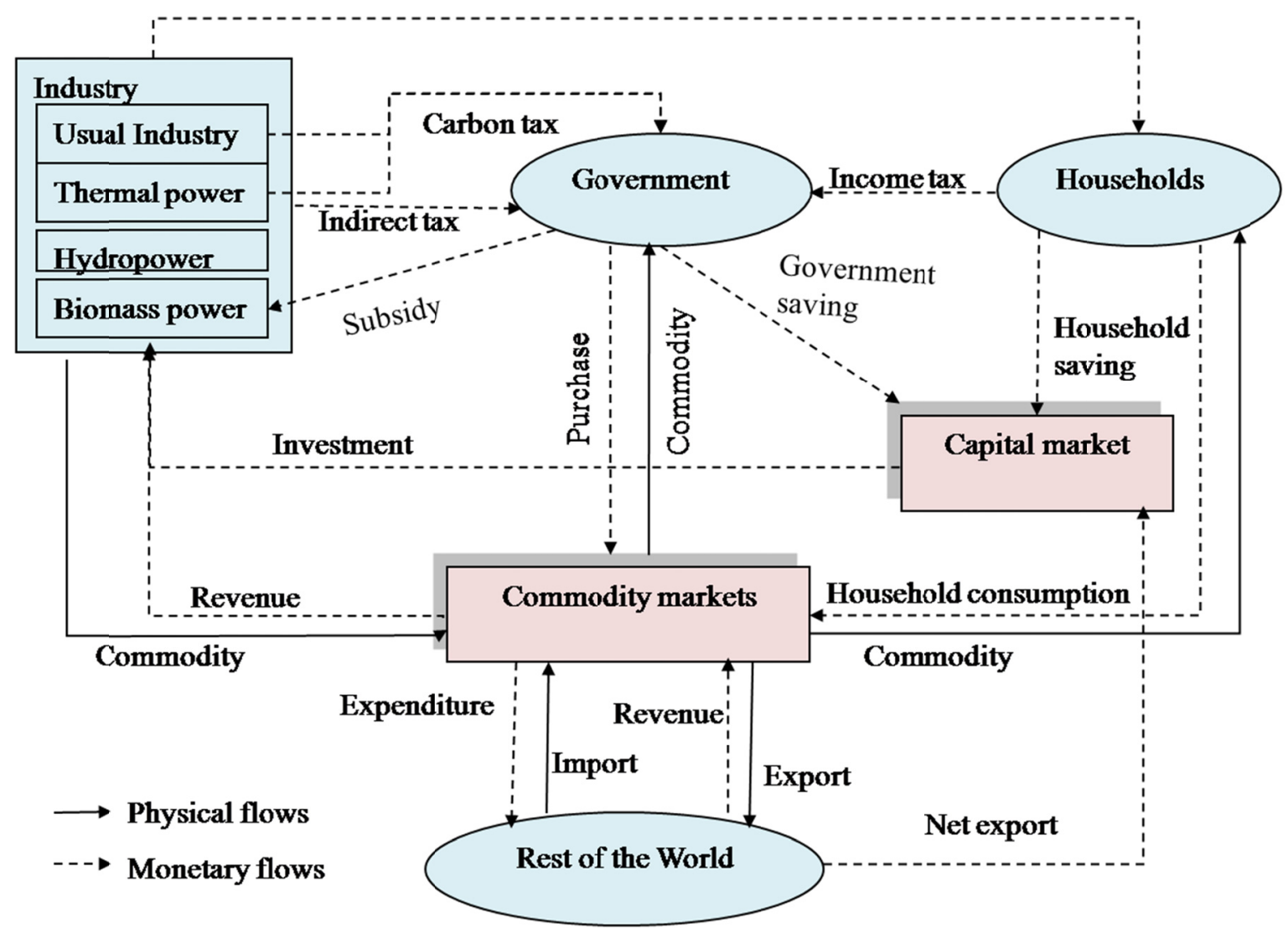

Figure 2. Relationships between economic entities

Concerning the industry classifications, this study adopts the "2007 Input-output table of China" categories to evaluate changes in industrial structure (NBS, 2009). As indicated in Table 1, there are four industries in our model, and usual industry can be divided into 14 sectors. The output of each sector follows a linear production function related to capital stocks through a fixed coefficient.

Table 1. Classification of industries in this model

\begin{tabular}{lll}
\hline Industry & Sector & Sector \\
\hline Usual industry & Agriculture & Metal \\
& Mining & Other \\
& Light & Production \\
& Petroleum & Production of Water \\
& Chemical & Construction \\
& Nonmetal & Transport and postal services \\
Thermal power industry & Smelting & Other services \\
Hydropower industry & Thermal power & \\
Biomass power generation industry & Hydropower & \\
\hline
\end{tabular}

\subsection{Case Setting}

The first of three cases is the business as usual (BAU) case, which is a simulation of maintaining the present development trajectory. We use the same GHG emissions constraint in Case 1 and Case 2. To evaluate the effect of an environmental tax, we introduce a carbon tax in Case 2. Considering that the government is expected to 
levy a carbon tax at a low level starting in 2012 (NDRC, 2010), we set the carbon tax rate as $10 \mathrm{Yuan} / \mathrm{ton} \mathrm{CO}_{2} \mathrm{e}$, much lower than the price of a certificated emissions reduction (CER), which is $80 \mathrm{Yuan} / \mathrm{ton} \mathrm{CO}_{2} \mathrm{e}$ in the CDM market. In this model, the carbon tax will be levied on usual industries and the thermal power industry starting in 2012. This carbon tax is a special tax, the entirety of which will be used as a subsidy to develop biomass power.

Table 2. Case setting

\begin{tabular}{lll}
\hline & GHG emissions constraint & Environmental tax introduction \\
\hline BAU & Without & Without \\
Case 1 & With & Without \\
Case 2 & With & With \\
\hline
\end{tabular}

\subsection{Simulation Model Formulation}

In this model, the variables are of two types: endogenous (en) and exogenous (ex). The exogenous variables are given based on annual data, and the simulation stipulates the endogenous variables. The dynamic model is composed of greater than 50 mathematical equations. Due to space limitations, only the most important formulas are presented below.

(1) Objective function

The objective function is to maximize China's GDP from 2007 to 2020 :

$$
\begin{gathered}
M A X \sum_{t} G D P(t) \\
G D P(t)=V_{u} X_{u}(t)+V_{m} X_{m}(t)+V_{r} X_{r}(t)+V_{b} X_{b}(t)
\end{gathered}
$$

where, $\operatorname{GDP}(\mathrm{t})$ is the gross domestic production in term $\mathrm{t}(\mathrm{en}), \mathrm{X}_{\mathrm{i}}$ is the production of each industry $\mathrm{i}$ in term $\mathrm{t}$ (en), $V_{i}$ is the added value rate (ex), subscript $u$ is usual industries or goods, subscript $m$ is the thermal power industry, subscript $r$ is the hydropower industry, subscript $b$ is the biomass power generation industry and subscript $\mathrm{e}$ is the electricity service.

\section{(2) GHG Emissions}

The GHG emissions in this model are defined as the total quantity of anthropogenic emissions by sources of GHG emissions, including emissions by industries, household consumption and the treatment of biomass waste. According to 2006 IPCC guidance (IPCC, 2006), it is assumed that $\mathrm{CO}_{2}$ emissions from surplus biomass residues do not lead to changes of carbon pools in the land use, land use change and forestry sectors. Because $\mathrm{N}_{2} \mathrm{O}$ emissions in the process are very small, only $\mathrm{CH}_{4}$ is included in the calculation of the GHG emissions from the open burning of straw crops:

$$
G H G(t)=e f_{u} X_{u}(t)+e f_{m} X_{m}(t)+e f_{r} X_{r}(t)+e f_{b} X_{b}(t)+e f_{c} C(t)+e f_{s t w} S T W(t)
$$

where, GHG(t) is the GHG emissions in term $\mathrm{t}(\mathrm{en})$, $\mathrm{ef}_{\mathrm{i}}$ is the GHG emissions factor of industry $\mathrm{i}(\mathrm{ex})$, ef $(\mathrm{i})$ is the GHG emissions factor of household consumption (ex), STW(t) is the quantity of straw crops in term $\mathrm{t}(\mathrm{en})$ and $\mathrm{C}(\mathrm{t})$ is household consumption (en).

\section{(3) Electricity Flow Balance}

The electricity flow balance module necessitates the balance between electricity demand and supply. In the simulation model, electricity supply (Supply(t), en) can be supported by three different types of electricity generation: thermal power, hydropower and biomass power. To evaluate the mitigation effects of biomass power, the generation of hydropower is fixed as the base year over the simulation period in the model. Electricity demand (Demand(t), en) is determined by each of the industrial production types and household activities. To maintain the electricity flow balance, the electricity supply must meet the electricity demand in each year.

$$
\begin{gathered}
\operatorname{Demand}(t)=D_{e u} X_{u}(t)+D_{e m} X_{m}(t)+D_{e r} X_{r}(t)+D_{e b} X_{b}(t)+D_{e c} C(t) \\
\operatorname{Supply}(t)=T P(t)+H P(t)+B P(t) \\
\operatorname{Supply}(i, t)=\operatorname{Demand}(i, t)
\end{gathered}
$$

where, Demand(t) is the total electricity demand in term $t(e n), D_{e_{i}}(j)$ is the electricity demand coefficient of industry $i(e x)$, supply(t) is the total electricity supply in term $t(e n), T P(t)$ is the thermal power supplied in term $t$ (en), $\mathrm{HP}(\mathrm{t})$ is the hydropower supplied in term $\mathrm{t}(\mathrm{en})$ and $\mathrm{BP}(\mathrm{t})$ is the biomass power supplied in term $\mathrm{t}(\mathrm{en})$. 
(4) Commodity flow balance

Based on a standard input-output model, balance in the row must be maintained.

$$
X_{u}(t) \geq A_{u u} X_{u}(t)+C_{u}(t)+G_{u}(t)+I_{u}(t)+E_{u}(t)-M_{u}(t) \quad(\mathrm{u}=1 . .14)
$$

where, $X_{u}(t)$ should meet the output balance between the industries, household consumption $\left(\mathrm{C}_{\mathrm{u}}(\mathrm{t})\right.$, en), government consumption $\left(\mathrm{G}_{\mathrm{u}}(\mathrm{t})\right.$,ex), investment $\left(\mathrm{I}_{\mathrm{u}}(\mathrm{t})\right.$, en), exports $\left(\mathrm{E}_{\mathrm{u}}(\mathrm{t})\right.$, ex) and imports $\left(\mathrm{M}_{\mathrm{u}}(\mathrm{t})\right.$, en).

(5) Value flow balance

Similar to the row balance in the input-output table, the balance in the column must also be maintained.

$$
\begin{gathered}
P_{u} X_{u} \leq P_{u} A_{u u} X_{u}+P_{e} A_{e u} X_{u}+Y h_{u}+\operatorname{depr}_{u} K_{u}+\operatorname{itax}_{u} X_{u}+t_{c} e f_{u} X_{u} \\
P_{m} X_{m} \leq P_{u} A_{u m} X_{m}+P_{e} A_{e m} X_{m}+Y h_{m}+\operatorname{depr}_{m} K_{m}+\operatorname{itax}_{m} X_{m}+t_{c} e f_{m} X_{m} \\
P_{r} X_{r} \leq P_{u} A_{u r} X_{r}+P_{e} A_{e r} X_{r}+Y h_{r}+\operatorname{depr}_{r} K_{r}+\operatorname{itax}_{r} X_{r}+t_{c} e f_{r} X_{r} \\
P_{b} X_{b}+\operatorname{sub} \leq P_{u} A_{u b} X_{b}+P_{e} A_{e b} X_{b}+Y_{b}+\operatorname{depr}_{b} K_{b}+\operatorname{itax}_{b} X_{b} \\
s u b=t_{c} e f_{u} X_{u}+t_{c} e f_{m} X_{m}
\end{gathered}
$$

where, $\mathrm{P}_{\mathrm{i}}$ is the price rate (en), $\mathrm{P}_{\mathrm{i}} \mathrm{X}_{\mathrm{i}}$ should maintain the input balance between the industries, gross household income $\left(\mathrm{Yh}_{\mathrm{i}}\right.$, en), depreciation $\left(\mathrm{depr}_{\mathrm{i}} \mathrm{X}_{\mathrm{i}}\right.$ : en), indirect tax $\left(\mathrm{itax}_{\mathrm{i}} \mathrm{X}_{\mathrm{i}}\right.$, en), carbon tax $\left(\mathrm{t}_{\mathrm{c}} \mathrm{e}_{\mathrm{i}} \mathrm{X}_{\mathrm{i}}\right.$, en) and subsidies to biomass power industry (sub, en).

(6) Production function

$$
\begin{gathered}
X_{i} * h_{i}=K_{i} \\
K_{i}(t+1)=(1-\operatorname{depr}(i)) * K_{i}(t)+d l t_{-} K_{i}(t+1)
\end{gathered}
$$

where, $h_{i}$ is the capital input coefficient (capital input quantity per unit production) in industry $i(e x)$ and $K_{i}$ is the capital stock of industry $i$ in term $t(e n)$.

\section{Results}

A robust and credible model is crucial to policy evaluation, particularly when we must consider the relationships between energy consumption, industry structure adjustment and GHG emissions. Even one slightly different assumption could result in significant discrepancies between different model results. Thus, we first calibrate the model by comparing the simulation results of the base year with the actual value.

\subsection{Calibration of the Model}

Running the simulation returns the following results: the GDP for the base year is 26,604 billion Yuan, and the GHG emissions for the base year are 6,423 million ton $\mathrm{CO}_{2} \mathrm{e}$, with errors of 1 percent and 2.18 percent, respectively, compared with the 2007 values. The simulation results are well within the usual margins of error; therefore, the model reflects actual social, economic and environmental development with high reliability.

\subsection{Economic Development and GHG Emissions Trends}

In this model, the objective function is to maximize the total GDP from 2007 to 2020, subject to a series of constraints, such as a GHG emissions constraint, the electricity supply and demand balance, the commodity flow balance, and the value flow balance. As indicated in Figure 3, without a GHG emissions constraint, GDP will develop at the fastest pace in the BAU case, while GHG emissions would reach the highest level. Comparing the BAU case and Case 1 illustrates that economic development will be greatly decreased with the GHG emissions constraint. However, when we introduce an environmental tax to promote biomass power development in Case 2 with the same GHG emissions constraint as Case 1, GDP increases. Therefore, the introduction of an environmental tax can promote economic development. According to the simulation, the average annual growth rate of GDP will be 9 percent with the introduction of an environmental tax.

The simulation indicates that GHG emissions will continue to increase from 2007 to 2020 in each case. GHG emissions will be 16,937 million ton $\mathrm{CO}_{2} \mathrm{e}$ in 2020 without the GHG emissions constraint, which reflects the urgency of GHG emissions mitigation in China. In this model, we use the same GHG emissions constraint in Case 1 and Case 2, 12,846 million ton $\mathrm{CO}_{2} \mathrm{e}$, which is twice the 2007 level. Comparing the GHG emissions in Case 1 and Case 2, it is found that with the introduction of environmental tax, the accumulated GHG emissions reduction from 2007 to 2020 is 993 million tons $\mathrm{CO}_{2} \mathrm{e}$. Although small, this reduction illustrates the potential mitigation effects of an environmental tax. 


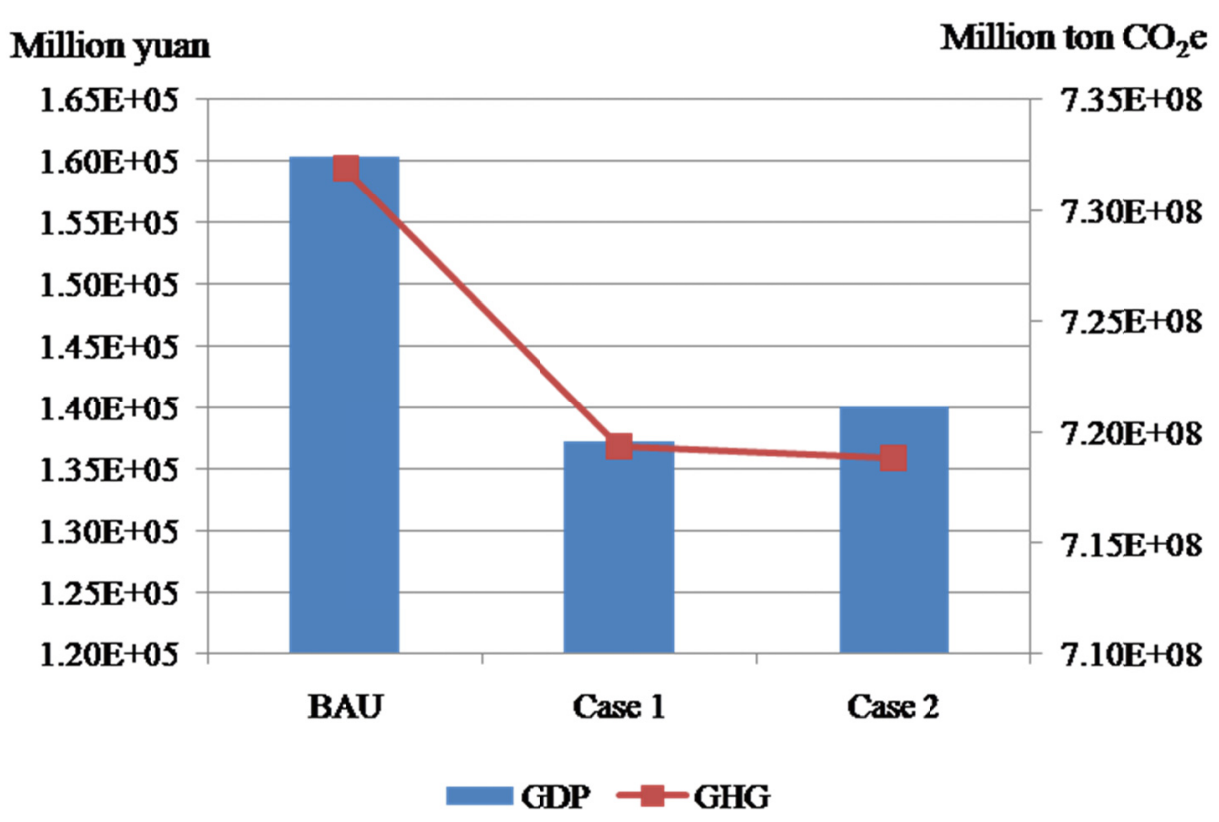

Figure 3. Total GDP and GHG emissions from 2007 to 2020

\subsection{Biomass Power Development}

With a subsidy from the $10 \mathrm{Yuan} /$ ton $\mathrm{CO}_{2}$ e carbon tax, the biomass power industry will be developing starting in 2012. The total revenue from the carbon tax from 2012 to 2020 is 954 billion Yuan, all of which will be used as subsidy for the biomass power industry. The incentive effects are obvious, as indicated in Figure 4, which illustrates that total biomass power generation will reach $2336.98 \mathrm{TWh}$ in 2020.

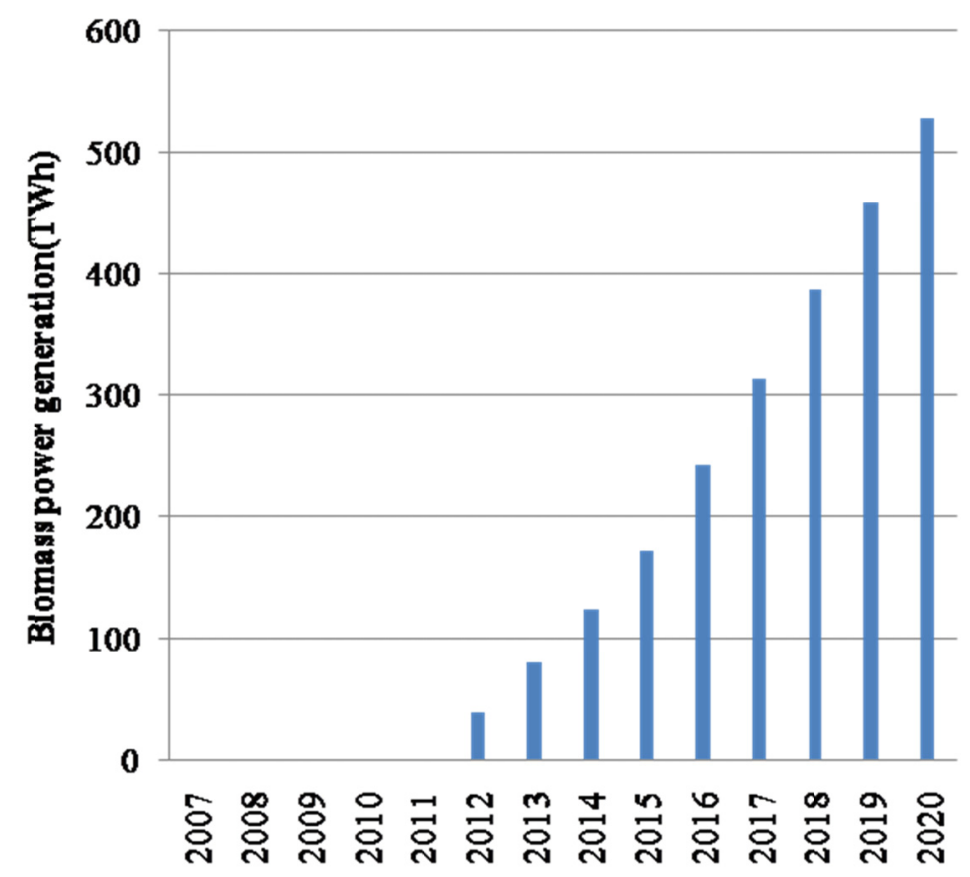

Figure 4. Development of Biomass power in Case 2

However, thermal power is still responsible for the majority of power generation over the entire period. To maintain rapid economic development, electricity demand will continue to increase. As indicated in Figure 5, the 
quantity of the electricity supply is climbing to $6632.41 \mathrm{TWh}$ in 2020 , twice the 2007 level. Although the biomass power industry would see considerable development with the introduction of an environmental tax, it would only contribute 8 percent to the total electricity supply in 2020, when the proportion of thermal power would still be above 80 percent. The dominance of thermal power illustrates the need to pursue development of other types of renewable energy power generation along with biomass power, such as hydropower, wind power and solar power.

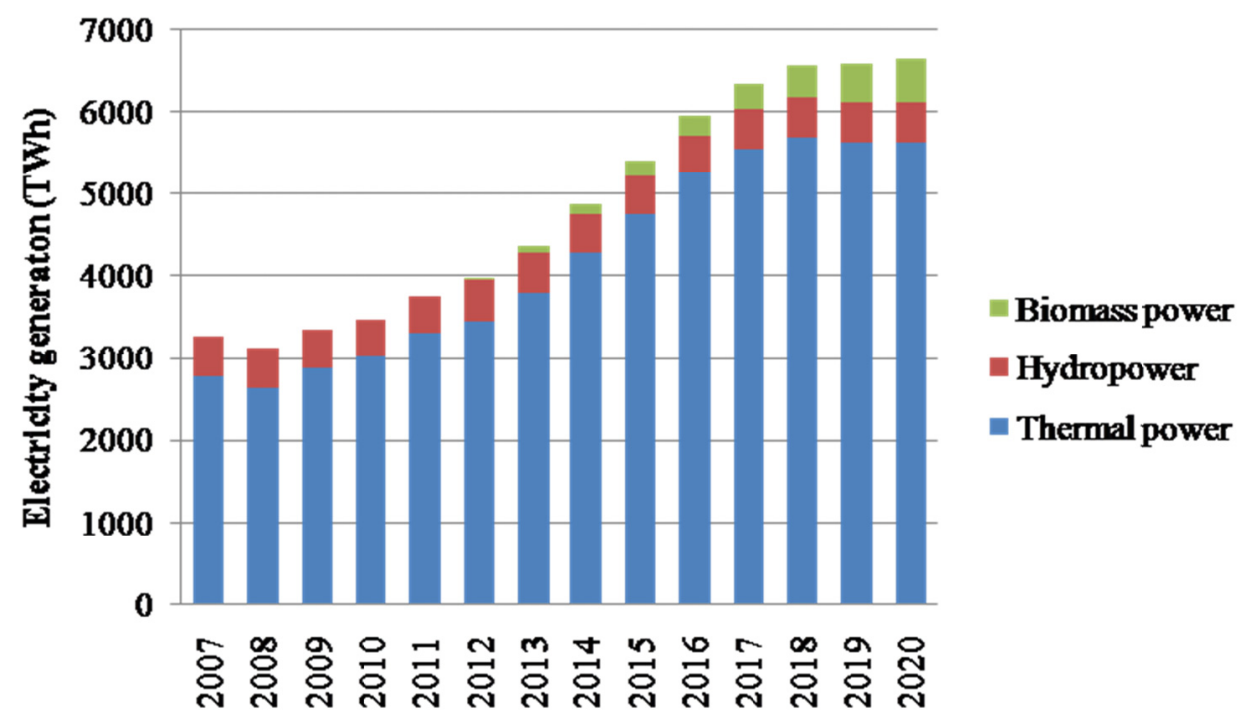

Figure 5. Electricity-supply structure in Case 2

As the raw material of the biomass power industry, the level of straw crop utilization increases with the rapid development of the biomass power industry. With the introduction of an environmental tax, nearly 1.70 billion tons of straw crops can be used from 2007 to 2020, and the utilization rate of straw crops is increased to 20 percent in 2020 .

\subsection{GHG Intensity}

Prior to the Copenhagen Climate Summit in 2009, China promised to reduce its GHG emissions per unit of GDP by 40 to 45 percent by 2020 compared to the 2005 level (Ministry of Commence, 2009). Thus, in 2020 the GHG intensity will be reduced to $0.155-0.169 \mathrm{kgCO}_{2} \mathrm{e} /$ Yuan in China. However, there are many debates about the credibility and stringency of this climate commitment (Zhang, 2010), which focuses on whether such a commitment is truly a challenge or merely represents business as usual. However, until now, the government has not released any scientific basis for making this climate commitment. Therefore, it is unclear how reasonable this climate commitment is. Moreover, given that China's climate commitment is in the form of GHG intensity, which is a relative rather than an absolute value, we cannot obtain information on the emissions levels in the future. Therefore, it is necessary to establish a total quantity target for GHG emissions in China.

Through the simulation, we obtain the GHG intensity from 2007 to 2020 in each case, as indicated in Figure 6. In 2020, the GHG intensities in the BAU case, Case 1 and Case 2 are 0.184, 0.155, and 0.150 $\mathrm{kgCO}_{2} \mathrm{e} / \mathrm{Yuan}_{\text {, }}$ respectively, and the climate commitment can be achieved in Case 1 simply by the optimization of industrial structures, which calls for the development of a tertiary industry. In Case 1, the proportion of the tertiary industry in GDP will be 56 percent in 2020, which will be a great challenge and difficulty for China. Although the 45 percent reduction target can be reached with the Case 1 scenario, we cannot determine the credibility of the commitment or the rationality of the model arbitrarily. With the introduction of the $10 \mathrm{Yuan} / \operatorname{tonCO} \mathrm{O}_{2} \mathrm{e}$ carbon tax, the GHG intensity in 2020 can be reduce by 46.5 percent compared with 2005 levels. 


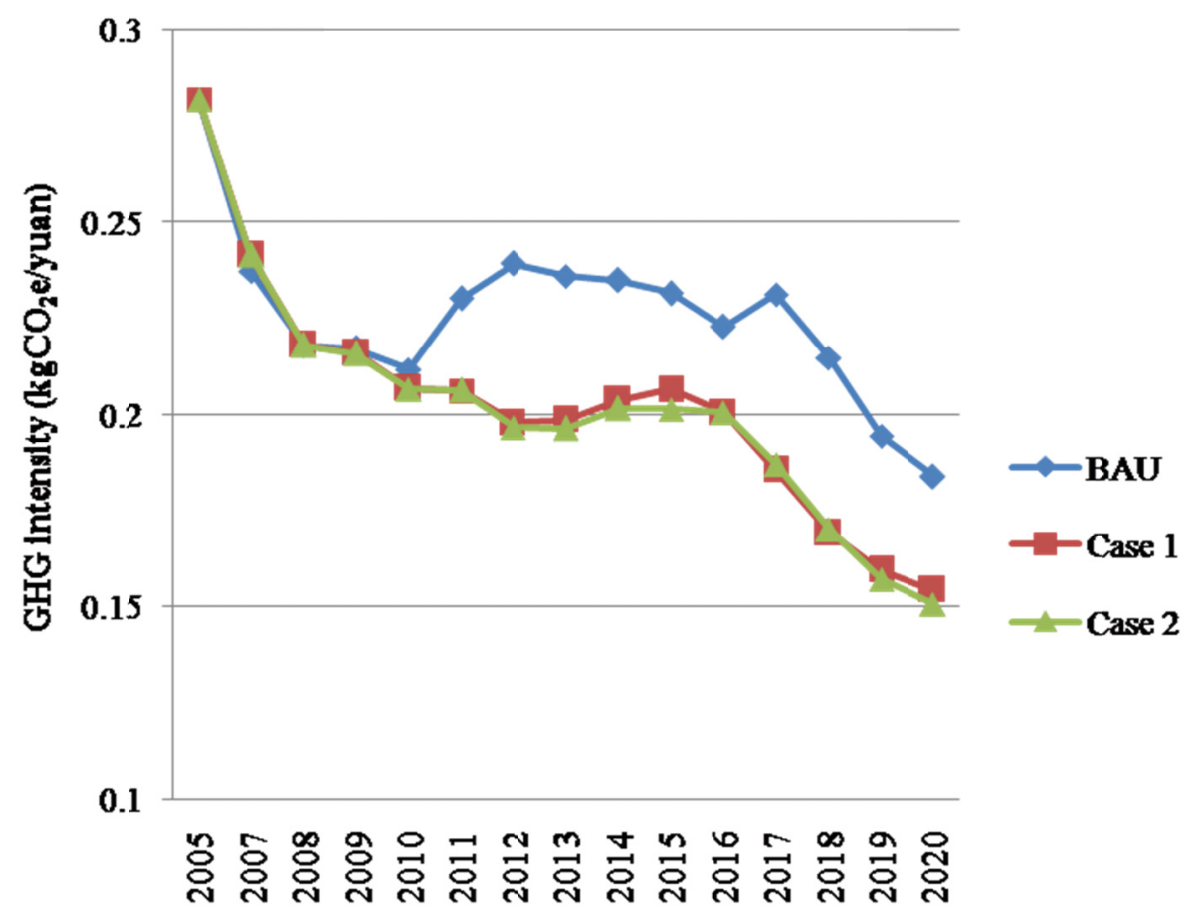

Figure 6. GHG intensity trends from 2007 to 2020

\subsection{Industrial Structure Adjustment}

An industrial structure adjustment will be another key method to promote economic development and satisfy the GHG emissions constraint. There are seventeen sectors in this model, and we choose two typical sectors for discussion, the thermal power sector and the metal smelting sector.

The thermal power sector is an important electricity supplier in the model. Though its GHG emissions factor is the highest of the seventeen sectors, the thermal power sector still maintains the increasing trend with the GHG emissions constraint. With the introduction of an environmental tax, biomass power is being developed to substitute the equivalent amount of thermal power. Therefore, the production curve of the thermal power sector is lowest in Case 2.

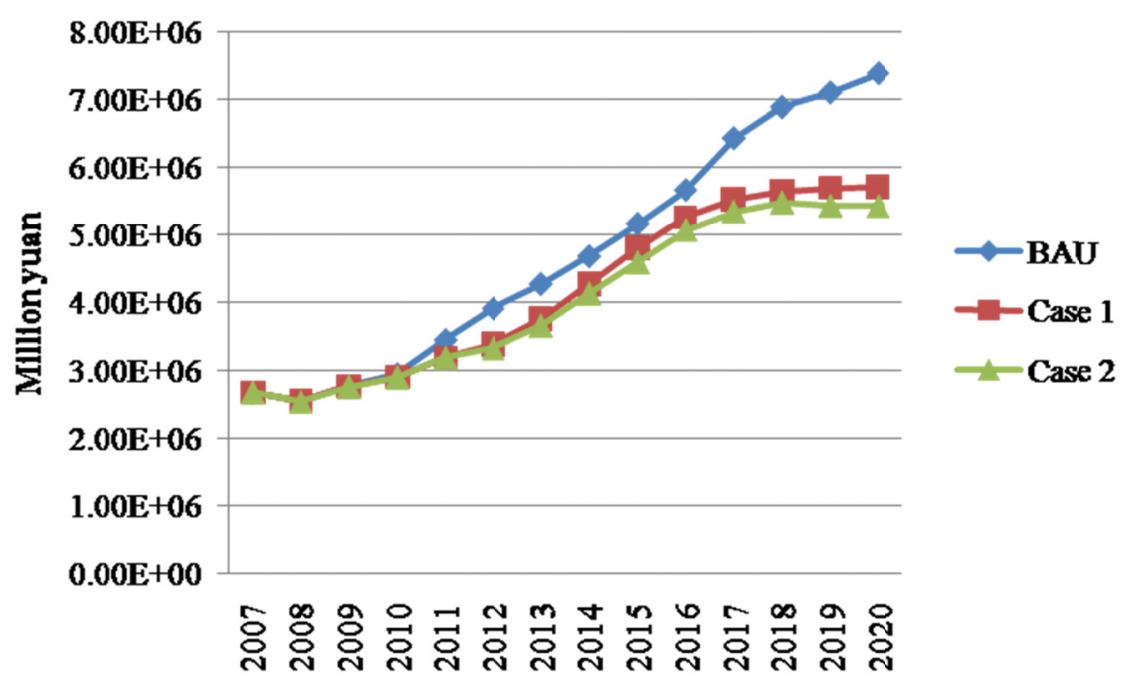

Figure 7. Production trend of the thermal power sector from 2007 to 2020 
As an energy-intensive sector, the metal smelting sector has the second highest GHG emissions factor of the seventeen sectors, and the effect of industrial structure optimization on this sector is made obvious by the simulation.

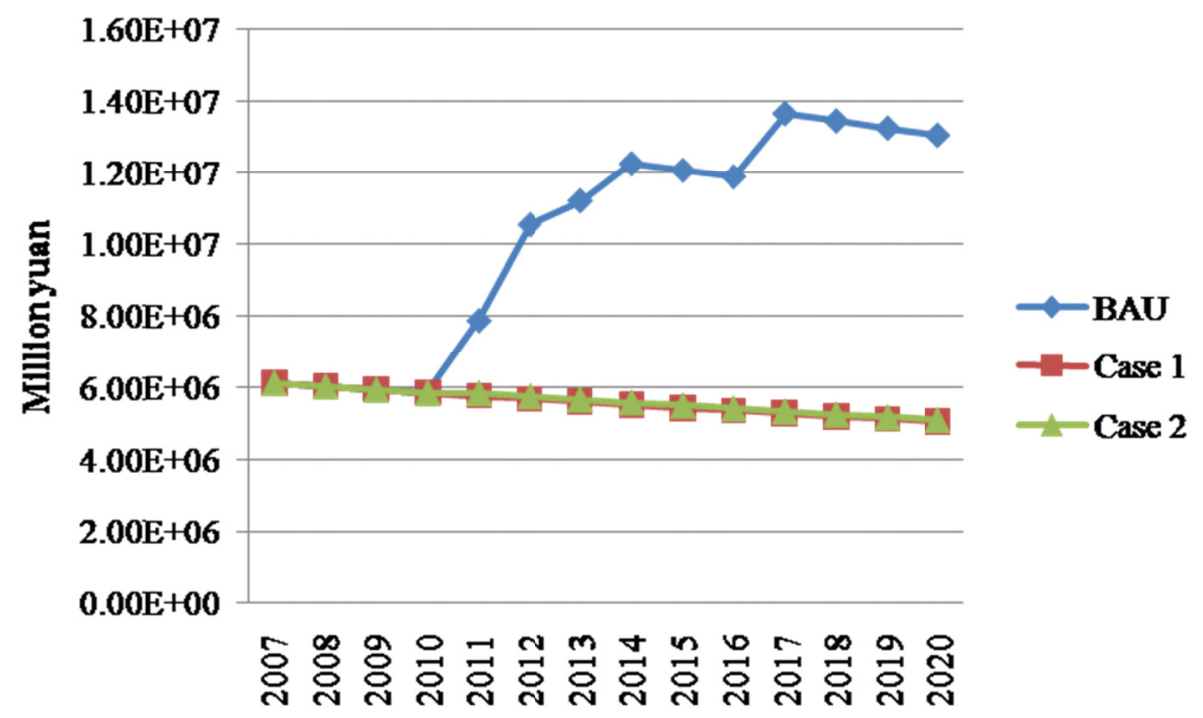

Figure 8. Production trend of the metal smelting sector from 2007 to 2020

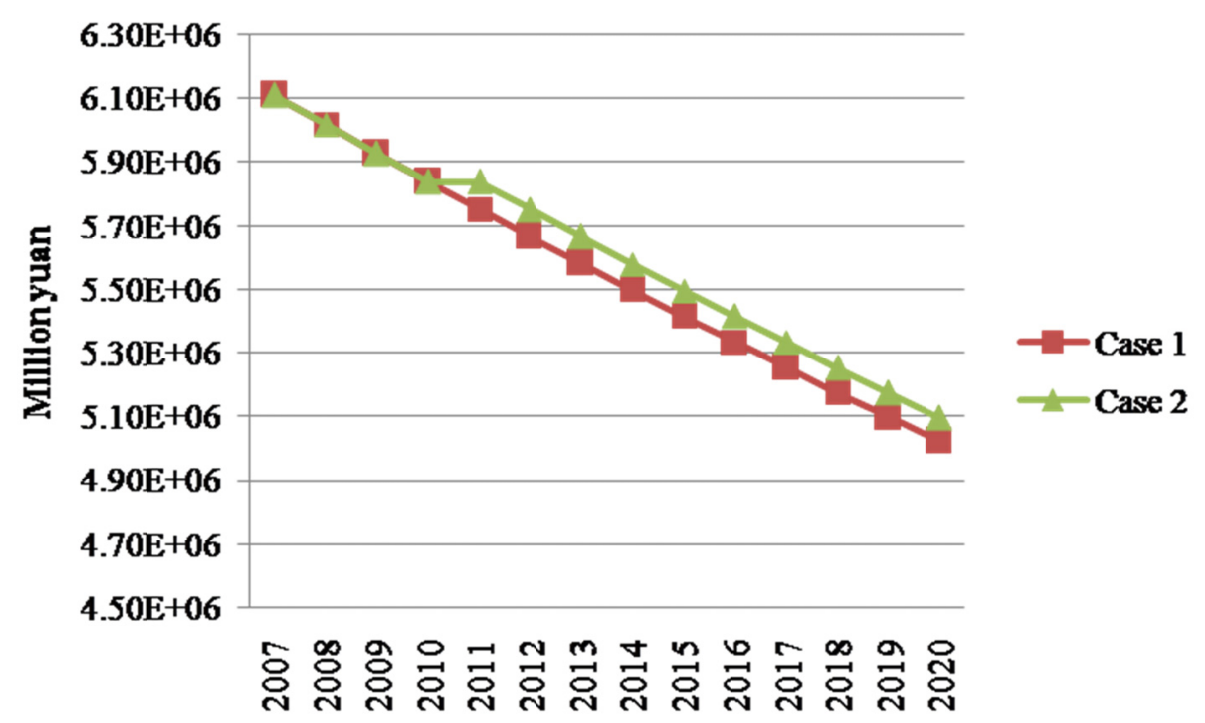

Figure 9. Production Comparison of the metal smelting sector in Case 1 and Case 2

As indicated in Figure 8, to maximize economic development, the production of the metal smelting sector increases considerably from 2007 to 2020 in the BAU case. With the GHG emissions constraint in Case 1 and Case 2, production declines. Given the loose GHG emissions constraint, twice the 2007 level, the declining range of the metal smelting sector's production in the case without an environmental tax (Case 1) is not terribly dramatic compared with the case that includes a 10 Yuan/ton $\mathrm{CO}_{2} \mathrm{e}$ carbon tax (Case 2), as indicated in Figure 9. However, we find that with the introduction of an environmental tax, the production of the metal smelting sector increases a small amount. This increase implies that to achieve the GHG emissions constraint, the model must sacrifice the development of energy-intensive sectors. However, when we introduce an environmental tax for the biomass power industry, GHG emissions will be reduced by the substitution of biomass power for thermal power, and, therefore, the energy-intensive sectors will not need to be sacrificed as much as without an environmental tax. 


\subsection{Economic Feasibility}

Economic feasibility is an important indictor for policymaking, and we adopt the cost-benefit analysis method to evaluate the feasibility of the proposed policy. In the following formula, if the feasibility value is greater than one, it is feasible for the proposed policy. Otherwise, it is infeasible.

$$
\text { Feasibilit } y=\text { Benefit / Cost }
$$

Where feasibility is the economic feasibility of the proposed policy, benefit is the accumulated increase of GDP in Case 2 compared with Case 1 from 2007 to 2020, and cost is the total investment of in the biomass power industry in Case 3 over the same period.

Based on the simulation, the accumulated increase in GDP is 1,550 billion Yuan, and the total investment in the biomass power industry is 226 billion Yuan. Therefore, the proposed policy is proven to be economically feasible.

$$
\text { Feasibilit } y=1.55 * 10^{6} / 2.26 * 10^{5}=6.86
$$

\section{Discussion and Conclusion}

\subsection{Discussion}

With the recent growing focus on China's electricity supply and GHG mitigation, a range of studies of China's electricity and GHG emissions outlook have been developed across different institutions, such as China Energy Research Institute's 2050 China Energy and $\mathrm{CO}_{2}$ emissions report (ERI, 2009). We compare ERI's study with ours in aspects of methodologies and scenarios, as well as electricity and emissions outlook.

Although both studies reviewed the emission outlook for China to 2020 or later, they differ in the modeling methodologies. The model used by ERI is a hybrid model which combines a top-down CGE model of 20 sectors with a bottom-up IPAC/AIM technology assessment model. Our study employs a top-down input-output model. The study by ERI has a baseline scenario (BS) and an alternative scenario (AS). Table 3 is the comparison of total electricity, GHG emissions and GHG intensity in both studies. Firstly, electricity demand in 2020 of both studies is in the range of 6,000- 8,000TWh. Secondly, our study's GHG emission is higher than ERI's study. It can be illustrated in two aspects. On one hand, only biomass power generation is considered in our study, not including other renewable energy power generation and nuclear power, which are considered in ERI's study. On the other hand, GHG emission from open-burning of crop straw is included in our study, but ERI does not calculate this part. Thirdly, though GHG intensity of our study's alternative scenario is $0.150 \mathrm{~kg} \mathrm{CO} 2 \mathrm{e} / \mathrm{yuan}$, higher than that of ERI's study, both studies stand for the conclusion that the 2020 reduction target established by Chinese government can be accomplished. In sum, the simulation results of our study are reliable through comparison with ERI's study.

Table 3. Comparison of electricity demand and GHG emission in 2020

\begin{tabular}{llllll}
\hline & $\begin{array}{l}\text { Electricity } \\
(\mathrm{TWh})\end{array}$ & $\begin{array}{l}\text { GHG } \\
\left(\text { Million ton } \mathrm{CO}_{2} \mathrm{e}\right)\end{array}$ & $\begin{array}{l}\text { GHG intensity } \\
\left(\mathrm{kg} \mathrm{CO}_{2} / \text { yuan }\right)\end{array}$ & $\begin{array}{l}\text { Reduction } \\
2005(\%)\end{array}$ & \\
\hline ERI-BS & 6,527 & 10,190 & 0.157 & $44 \%$ & \\
ERI-AS & 5,676 & 8,290 & 0.128 & $55 \%$ & \\
Ours-BAU & 8,129 & 16,936 & 0.184 & $34 \%$ & \\
Ours-Case 1 & 6,401 & 12,846 & 0.154 & $45 \%$ \\
Ours-Case 2 & 6,632 & 12,846 & 0.150 & $46 \%$ & \\
\hline
\end{tabular}

\subsection{Conclusion}

With the highest GHG emissions in the world, China is facing significant mitigation pressure. In 2009, China made a commitment to the climate to reduce its GHG intensity by $40-45$ percent by 2020 compared to the 2005 levels. Subsequently, the government expressed the expectation of levying a carbon tax during the $12^{\text {th }}$ five-year program (NDRC, 2010). In this context, this study evaluates the effects and feasibility of introducing a 10 Yuan/ton $\mathrm{CO}_{2} \mathrm{e}$ carbon tax in 2012 in China with a dynamic time-recursive input-output model. The simulation results prove that the introduction of an environmental tax is effective and economically feasible to achieve the sustainable development targets in China. 
The results indicate the following: 1) Based on the simulation, the annual growth rate of GDP is 9 percent in the case with the carbon tax. Compared to the case without the environmental tax, the total GDP will be increased by 1,550 billion Yuan, and the total GHG will be reduced by 993 million ton $\mathrm{CO}_{2} \mathrm{e}$ from 2007 to 2020 in the case with carbon tax. Therefore, the introduction of an environmental tax would promote economic development and reduce GHG emissions. Moreover, the GHG intensity in 2020 will be $0.15 \mathrm{kgCO}_{2} \mathrm{e} / \mathrm{Yuan}$, a 46.5 percent reduction compared to the 2005 levels. 2) The total electricity generation of biomass power from 2007 to 2020 will reach 2336.98 TWh but will not be able to significantly reduce the dominance of thermal power in China. Apart from electricity substitution, industrial structure adjustment is another key method to achieve the dual targets of economic development and GHG emissions mitigation. 3) The cost-benefit analysis found that it is feasible to introduce an environmental tax to promote biomass power development. 4) The study can also provide a useful and effective method to evaluate the environmental policy by constructing a comprehensive input-output model, and the findings of this research can provide a scientific basis for policy decisions.

There are several factors that this study has not addressed. First, this study does not take into account the geographical diversity of straw crop distribution and only adopts the straw crops available nationally as raw materials for the biomass power industry. Meanwhile, with respect to an environmental tax, this study uses a 10 Yuan/tCO $/ \mathrm{CO}_{2} \mathrm{e}$ carbon tax, which is much lower than the current CER price of $80 \mathrm{Yuan} / \mathrm{tCO}_{2} \mathrm{e}$ in the $\mathrm{CDM}$ market. Perhaps future studies should simulate the carbon tax rates at different levels, such as $10 \mathrm{Yuan} / \mathrm{tCO}_{2} \mathrm{e}, 50$ Yuan/ $/ \mathrm{tCO}_{2} \mathrm{e}$ and 100 Yuan/ $/ \mathrm{CO}_{2} \mathrm{e}$, to choose the optimal tax rate for China. In addition, this study does not include the other types of renewable energy power generation, such as hydropower, wind power and solar power, which are important GHG emissions mitigation strategies in China. The three points above will be addressed in future studies.

\section{Acknowledgements}

This research is supported by grants from the Japan Society for the Promotion of Science (JSPS) (No. 23810002), and the "National Construction High Level University Government-sponsored Graduate Student Project" of the China Scholarship Council. The paper benefited from the valuable comments of anonymous reviewers.

\section{References}

Bi, Y. (2010). Study on straw resources evaluation and utilization in China. Dissertation submitted to Chinese Academy of Agricultural Sciences.

China Energy Research Institute (ERI). (2009). 2050 China Energy and $\mathrm{CO}_{2}$ Emissions Report. Beijing: Science Press.

Higano, Y. (1996). Derivation of environmental value-added tax based on the environmental programming model. Studies in Regional Sciences, 26, 181-187. http://dx.doi.org/10.2457/srs.26.181

Intergovernmental Panel on Climate Change (IPCC). (2006). 2006 IPCC Guidelines for National Greenhouse Gas Inventories. Published by the Institute for Global Environmental Strategies, Japan.

Leontief, W. (1966). Input-output Economics. New York: Oxford University Press.

Liu, G., \& Shen, L. (2007). Quantitative appraisal of biomass energy and its geographical distribution in China. Journal of Natural Resources, 22, 9-18.

Liu, H., Jiang, G., Zhuang, H., \& Wang, K. J. (2008). Distribution, utilization structure and potential of biomass resources in rural China: with special references of crop residues. Renewable and Sustainable Energy Reviews, 12, 1402-1408. http://dx.doi.org/10.1016/j.rser.2007.01.011

Li, Y., Zou, S., Xu, F., Yabar, H., \& Higano, Y. (2012). The impacts of introducing recycling taxes on China's environmental policy: case study on e-waste recycling. Journal of Sustainable Development, 5, 83-98. http://dx.doi.org/10.5539/jsd.v5n4p83

Ministry of Commerce. (2009). China announced the $\mathrm{CO}_{2}$ emission targets. Retrieved from http://www.mofcom.gov.cn/aarticle/i/jyjl/m/200911/20091106640294.html

National Development and Reform Commission of China (NDRC). (2007). China medium- and long-term renewable energy development planning. Retrieved from http://www.sdpc.gov.cn/zcfb/zcfbtz/2007tongzhi/t20070904_157352.htm

National Bureau of Statistics of China (NBS). (2009). Input-output table of China in 2007. Beijing: China Statistics Press.

National Development and Reform Commission of China (NDRC). (2010). China expected to levy carbon tax 
from 2012 at 10 Yuan/ton $\mathrm{CO}_{2}$ e. Retrieved from http://www.china5e.com/show.php?contentid=97433

National Development and Reform Commission of China (NDRC). (2011). Comprehensive utilization of straw crops in 12th Five-Year Plan. Retrieved from http://www.ndrc.gov.cn/zcfb/zcfbtz/2011tz/t20111219_451468.htm

Uchida S., \& Higano, Y. (2006). An Evaluation of Policy Measures against Global Warming by promoting effective use of potential energy in wastes. Studies in Regional Sciences, 36(1), 481-508.

Wu, C. Z, Huang, H., Zheng, S. P., \& Yin, X. L. (2002). An economic analysis of biomass gasification and power $\begin{array}{lllll}\text { generation in China. } & \text { Bioresource }\end{array}$ http://dx.doi.org/10.1016/S0960-8524(01)00116-X

Yang, Y. L., Zhang, P. D., Zhang, W. L., \& Tian, Y. S., Zheng, Y. H., \& Wang, L. S. (2010). Quantitative appraisal and potential analysis for primary biomass resources for energy utilization in China. Renewable and Sustainable Energy Reviews, 14, 3050-3058. http://dx.doi.org/10.1016/j.rser.2010.07.054

Zhang, Z. (2010). Assessing China's carbon intensity pledge for 2020: strigency and credibility issues and their implication. Ease-West Center Working Papers, 113, 1-18.

Zhao, Z. Y., Zuo, J., Fan, L. L., \& George, Z. (2011). Impacts of renewable energy regulations on the structure of power generation in China-A critical analysis. Renewable Energy, 36, 24-30. http://dx.doi.org/10.1016/j.renene.2010.05.015

Zhao, Z., \& Yan, H. (2012). Assessment of the biomass power generation industry in China. Renewable Energy, 37, 53-60. http://dx.doi.org/10.1016/j.renene.2011.05.017

Zhou, X. P., Wang, F., Hu, H. W., Yang, L., Guo, P. H., \& Xiao, B. (2011). Assessment of sustainable biomass resource for energy use in China. Biomass and Bioenergy, 35, 1-11. http://dx.doi.org/10.1016/j.biombioe.2010.08.006 